\title{
SMALL BOWEL OBSTRUCTION- CLINICAL FEATURES, BIOCHEMICAL PROFILE AND TREATMENT OUTCOME
}

\author{
Laitonjam Chinglensana1, Sunilkumar Singh Salam², Pankaj Saluja ${ }^{3}$, Yumnam Priyabarta4, Manoharmayum Birkumar Sharma 5
}

${ }_{1}^{1}$ Assistant Professor, Department of General Surgery, RIMS, Imphal, Manipur India.

${ }^{2}$ Assistant Professor, Department of General Surgery, RIMS, Imphal, Manipur India.

${ }^{3}$ Senior Resident, Department of General Surgery, RIMS, Imphal, Manipur India.

${ }_{4}^{4}$ Assistant Professor, Department of Radiodiagnosis, RIMS, Imphal, Manipur India.

5 Professor, Department of General Surgery, RIMS, Imphal, Manipur India.

\section{BACKGROUND}

ABSTRACT

Small bowel obstruction is defined as failure in forward propulsion of the contents in the intestine either due to dynamic or adynamic cause. It is a common surgical emergency requiring early diagnosis and corrective surgery. It presents a challenge to the surgeon. Studies in the west have shown that bowel obstruction accounts for at least $20 \%$ of all admissions to the surgical service. Aim: In view of varying aetiologies, intense study and clinical evaluation regarding trends and patterns of small bowel obstruction is worthwhile.

\section{MATERIALS AND METHODS}

The case series was conducted on 82 patients admitted in the Department of Surgery, Regional Institute of Medical Sciences (RIMS), Imphal, Manipur, from October 2013 to September 2015. Study was done through questionnaires and clinical examination, biochemical investigations including renal function tests, liver function tests, serum electrolytes, CT scan and CRP levels. Treatment modality was planned once the definitive diagnosis of bowel obstruction was made and data analysed using SPSS version 21.

\section{RESULTS}

$63(76.82 \%)$ cases were male, while $19(23.17 \%)$ were female giving a ratio of $3.3: 1$. The mean age was 37.50 years ranging from 13-94 years. Mechanical obstruction was the commonest type $92.68 \%$ followed by paralytic ileus in $6.1 \%$ cases. Abdominal distension was the commonest finding in $73 \%$, abdominal tenderness in $68.5 \%$ and elevated bowel sounds in $59.2 \%$. Previous abdominal scars were found in $32.4 \%$, while reduced bowel sounds were recorded in $26.1 \%$. Overall, adhesions and bands were the commonest cause of obstruction found in 56 (68.29\%) patients followed by strangulated hernias in 13 (15.85\%) patients and ileocaecal TB peritonitis in $8(9.76 \%)$ patients was the main cause of paralytic ileus. $45.12 \%$ patients had hyponatraemia, 13 $(15.85 \%)$ patients had hypokalaemia and $10(12.20 \%)$ patients had hyperkalaemia.

\section{CONCLUSION}

21-40 years' age group accounted for more than half of the patients, the most common cause being adhesions from previous abdominal surgeries followed by strangulated hernias. Plain abdominal x-rays were diagnostic in more than $60 \%$ of cases. Operative management was the mainstay of treatment in more than $2 / 3^{\text {rd }}$ of cases.

\section{KEY WORDS}

Small Bowel Obstruction, Laparotomy, Dynamic Obstruction, Paralytic Ileus.

HOW TO CITE THIS ARTICLE: Chinglensana L, Salam SS, Saluja P, et al. Small bowel obstruction- clinical features, biochemical profile and treatment outcome. J. Evolution Med. Dent. Sci. 2018;7(26):2972-2976, DOI: 10.14260/jemds/2018/670

\section{BACKGROUND}

Small bowel obstruction is a common surgical emergency that accounts for at least $20 \%$ of all admissions to a surgical service. ${ }^{1}$ It is defined as failure in forward propulsion of the contents in the intestine either due to dynamic or adynamic cause.2,3 Dynamic obstruction is a type of mechanical obstruction to the bowel caused by a physical blockage, which can either be extraluminal (Extrinsic), mural (Intrinsic) or intraluminal.

'Financial or Other Competing Interest': None.

Submission 13-05-2018, Peer Review 09-06-2018,

Acceptance 14-06-2018, Published 25-06-2018.

Corresponding Author:

Dr. Sunilkumar Singh Salam,

Chingamakha Ningthoujam Leikai Liwa Road,

Singjamei, Imphal-795001, Manipur, India.

E-mail: shoenil24@gmail.com

DOI: $10.14260 /$ jemds $/ 2018 / 670$
Whereas adynamic obstruction (Functional) is due to paralysed bowel without any mechanical cause. ${ }^{4}$ Mechanical obstruction often requires appropriate surgical treatment unlike functional obstruction, which mainly relies on nonoperative management.

Early diagnosis and immediate corrective measures usually bears a favourable prognosis. In the tropics patients are seen late with dehydration, circulatory collapse, biochemical derangements and sepsis due to poor healthcare facilities leading to considerable morbidity and mortality. The management of these patients therefore presents a serious challenge to the surgeon in a tropical environment.5,6 Depending on the site of obstruction, bowel obstruction can be of either small bowel obstruction or large bowel obstruction. Krebs HB et $\mathrm{al}^{7}$ studied the incidence of bowel obstruction and found that small bowel obstruction is far more common than the large bowel obstruction $(77 \%$ vs. $23 \%)$ respectively. 
In high small bowel obstruction vomiting occurs early, is profuse and causes rapid dehydration with minimal distension and little evidence of dilated small bowel loops on abdominal radiography. Whereas in low small bowel obstruction, pain is predominant with central distension and multiple dilated small bowel loops on abdominal radiography. These symptoms generally subside with good patient care, management and timely intervention, but it is also important to appreciate that consequences of small bowel obstruction can be life-threatening also sometimes if there is superimposed strangulation leading to ischaemic bowel. ${ }^{8}$ These cases with strangulation require intensive care management with timely intervention to save the life of the patient and to prevent any further complication.

In addition to signs and symptoms, there is change in the internal milieu of the body also. This is mainly due to the improper absorption, repeated vomiting, constipation all leading to the biochemical changes in the body. These biochemical changes have severe adverse effects on the body so the timely correction of these changes can save the patient from grave consequences like seizures, cardiac arrhythmias, acute renal failure and even death. The knowledge of these biochemical changes occurring in the body during small bowel obstruction helps the surgeon to decide further management plan. Small bowel obstruction is predisposed by varying underlying anomalies (Including congenital) and diseases. Among all the causes the most common causes of bowel obstruction include adhesions, neoplasm and herniation. ${ }^{9}$ Lower abdominal surgeries including appendectomies, colorectal surgery, gynaecologic procedures and hernia repairs confers a greater risk of adhesive small bowel obstruction.

In the first three or so decades of the 20th century, mortality from small bowel obstruction was very high.10 Although, the mortality due to acute small bowel obstruction is decreasing with better understanding of pathophysiology, improvement in diagnostic techniques, fluid and electrolyte correction, much potent anti-microbial and surgical management but still mortality ranges from 3\% for simple obstruction to as much as $30 \%$ when there is vascular compromise or perforation of the obstructed bowel. This is further influenced by the clinical setting and related comorbidities.

Kloiber ${ }^{11}$ of Germany (1919) emphasised the importance of x-ray in locating the level of obstruction. The presence of gas in the wall of the bowel is a highly significant sign of bowel necrosis. This was first demonstrated by Schorr ${ }^{12}$ in 1963. Amongst all the dynamic or adynamic causes, postoperative adhesions stand as the most important cause. This was also reported by Brewer et $\mathrm{al}^{13}$ who analysed 1000 consecutive abdominal surgeries in 1976 and reported an incidence of post-surgical small bowel obstruction to be $2.5 \%$, which are supposed to be due to post-surgical adhesions.

Miller $\mathrm{G}$ et $\mathrm{al}^{14}$ reported the recurrence of obstruction after abdominal operations and found that the likelihood of re-obstruction increases and the time to re-obstruction decreases with increasing number of previous episodes of obstruction.

Early diagnosis of small bowel obstruction, skilful operative management, proper technique during surgery and intensive postoperative treatment yield gratifying results.
Small bowel obstruction of any nature is a potential threat to life. Hence, the problem demands the best of clinical acumen of a surgeon. Being a common surgical problem confronted by general surgeons, small bowel obstruction forms a major surgery performed in surgical units. In view of plethora of aetiologies, small bowel obstruction needs an intense study and critical evaluation. In the management of small bowel obstruction, it was once said- "never let the sun rise and set in" in cases of small bowel obstruction, because about $5.5 \%$ of small bowel obstructions is ultimately fatal if treatment is delayed.

Regional Institute of Medical Sciences (RIMS), Imphal is the main referral and teaching hospital in Manipur and receives emergencies from neighbouring states as well as other parts of country. Patients presenting late have clinical and biochemical patterns, which may be different from other places where the patients have easy and fast access to the medical facilities. Clinical presentation, aetiological pattern, biochemical changes, management and outcome of small bowel obstruction patients requires detailed analysis.

Small bowel obstruction is associated with serious complications resulting in high morbidity and mortality unless promptly and properly managed. Studies done in the west have shown that bowel obstruction accounts for at least $20 \%$ of all admissions to a surgical service with more than 9000 deaths annually. The common causes in the west have been found to be adhesions, hernias and neoplasm. The trends and patterns of bowel obstruction have been shown to vary with time and therefore it was worthwhile to undertake this study.

\section{MATERIALS AND METHODS}

This is a case series conducted in the Department of Surgery, Regional Institute of Medical Sciences (RIMS), Imphal, Manipur, from October 2013 to September 2015 on patients aged more than 12 years, admitted in the surgical wards of RIMS, Imphal with the diagnosis of small bowel obstruction. Study population was chosen by Convenience Sampling and 82 patients of small bowel obstruction were admitted within the study period. Approval of the Institutional Ethics Committee, Regional Institute of Medical Sciences, Imphal was obtained and confidentiality was maintained. There was no conflict of interest.

The patients with the diagnosis of small bowel obstruction underwent routine biochemical investigations like renal function tests, liver function tests, serum electrolytes, CT scan and CRP levels. Post-operative observation of patients was carefully done to see for any complications. Regular follow-up of the treated patients was done. The result of the study was interpreted using SPSS software 21 version.

All cases of small bowel obstruction fulfilling the inclusion criteria were studied and recorded in the prescribed proforma for data collection with prior written consent from the patients in case of adults and parents or guardians in case of minor. A detailed history with reference to the duration of onset and associated symptoms was taken. A detailed physical examination was undertaken, and relevant laboratory investigations were performed during the initial clinical encounter. All necessary investigations like CBC (Complete Blood Count), Urine RE, Blood Sugar, LFT (Liver Function Test), KFT (Kidney Function Test), serum 
electrolytes, ultrasonography and x-ray were done. Total number of surgical procedures performed on patients with small bowel obstruction in General Surgery Department during this period was 52, while rest 30 patients were managed conservatively.

\section{RESULTS}

The age range was between 13 years to 94 years. Most of the patients were between 21 - 40 years accounting for $53.2 \%$, while the least group was above the age of 70 years (5.2\%). The youngest patient was 13 years old boy, whereas the oldest was 94 years old male patient. There were 63 (76\%) male patients and $19(24 \%)$ female patients giving a male-tofemale ratio of 3.2: 1 .

The most common presenting symptoms were abdominal pain in $96.1 \%$, vomiting in $87.3 \%$, constipation in $77.3 \%$ and abdominal distension in $66.4 \%$ of the cases. The main physical findings included abdominal distension in $73 \%$, abdominal tenderness in $68.5 \%$, increased bowel sounds in $59.2 \%$ and previous abdominal surgical scars in $32.4 \%$ of cases. Other signs included decreased bowel sounds in $26.1 \%$ of cases, dehydration recorded in $15.4 \%$, while tachycardia and visible peristaltic movements were recorded in $10.9 \%$ and $8.8 \%$ of cases respectively. Digital rectal examination was performed in $50.8 \%$ of the cases.

Abdominal distension was the commonest finding 73\%, abdominal tenderness $68.5 \%$ and elevated bowel sounds $59.2 \%$. Previous abdominal scars were found in $32.4 \%$, while reduced bowel sounds were recorded in $26.1 \%$. Mechanical obstruction was recorded in $76(92.68 \%)$ cases, paralytic ileus in 5 (6.1\%), while in $1(1.21 \%)$ the type was not determined.

The most commonly used investigation was plain abdominal x-rays with a diagnostic value of more than $60 \%$. Mechanical obstruction accounted for $92.68 \%$ as mechanical SBO. Paralytic ileus was found in $6.1 \%$ of the cases, while the type of obstruction was not determined in $1.6 \%$ of the cases. Overall, postoperative adhesions and bands (68.29\%) was the leading cause of small bowel mechanical obstruction followed by strangulated hernias in $15.85 \%$ of the cases. The main cause of paralytic ileus was tuberculous peritonitis in 9.76\% of the cases. Operative management was performed in $52(69.41 \%)$ patients depending on requirement, while 30 $(30.53 \%)$ patients were managed conservatively. Overall, adhesions and bands were the commonest cause of obstruction found in 56 (68.29\%) patients followed by strangulated hernias in $13(15.85 \%)$ patients and ileocaecal TB peritonitis in $8(9.76 \%)$ patients was the main cause of paralytic ileus.

of all strangulated hernias inguinal hernias were commonest $84.62 \%$, umbilical and femoral hernias were very rare, each accounting for around 7.69\%. Overall, operative management was instituted in $52(69.41 \%)$ patients, while the rest $30(30.53 \%)$ patients were managed conservatively. The main complications recorded were peritonitis in 11 (13.41\%), bowel gangrene in $9(10.97 \%)$ and septicaemia in $4(4.88 \%)$ cases. Less common complications included gut perforation in 2 cases, enterocutaneous fistula in one, burst abdomen in one and deep venous thrombosis (DVT) of the calf in one patient. The study shows $45.12 \%$ patients had hyponatraemia, $15.85 \%$ had hypokalaemia and hyperkalaemia in $12.20 \%$ of cases which was more in cases with strangulated hernia. Hypochloraemia was present in $29.26 \%$ of cases, whereas hyperchloraemia was present in $7.32 \%$ of cases. The overall mortality rate was $8.53 \%$ (7) of the 82 cases. This was higher in patients who presented late.

Complications were relatively fewer postoperatively $(9.76 \%)$. There was however a significant association between pre-operative peritonitis, pre-operative intestinal gangrene and post-operative wound infection and fistula formation.

Majority of $51(62.19 \%)$ were discharged within the first one week, $24(29.27 \%)$ were discharged within the second week, while 7 (8.54\%) stayed in hospital for more than two weeks.

There is a significant association between duration of symptoms and mortality. There is an increase in mortality with increase in duration of symptoms.

The study shows that $45.12 \%$ patients had hyponatraemia with delayed presentation of around 5 days, whereas those patients with early presentation do not have significant changes in the sodium levels. No patients with small bowel obstruction had hypernatraemia. Of the total 82 patients with small bowel obstruction 13 patients had hypokalaemia with an average time of presentation around 4 days, 10 patients had hyperkalaemia with more delayed presentation of around 6 days of symptoms. Around 59 patients with early presentation had normal potassium levels. Patients with delayed presentation of around 5 days had low chloride levels, whereas 6 patients had high chloride levels. 52 patients with early presentation had normal potassium levels.

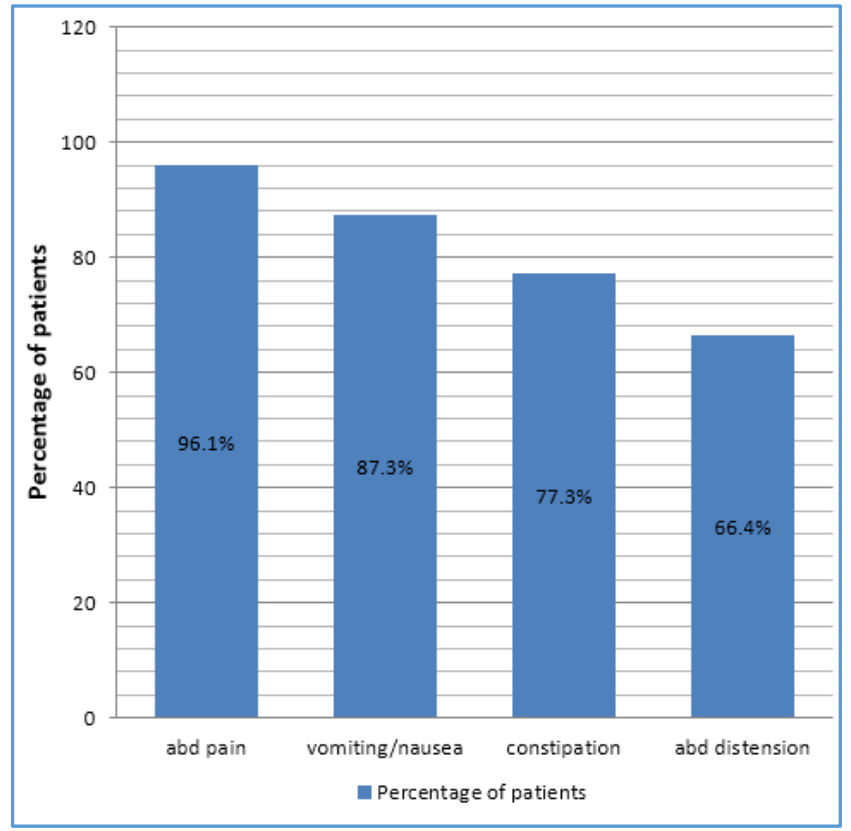

Figure 1. Symptoms

\begin{tabular}{|c|c|c|}
\hline Finding & $\begin{array}{c}\text { No. of } \\
\text { Patients }\end{array}$ & $\begin{array}{c}\text { \% of Total } \\
\text { Patients }\end{array}$ \\
\hline Abdominal distension & 60 & $73 \%$ \\
\hline Abdominal tenderness & 56 & $68.5 \%$ \\
\hline Inc. Bowel sounds & 48 & $59.2 \%$ \\
\hline Abdominal scar & 26 & $32.4 \%$ \\
\hline Decreased bowel sounds & 21 & $26.1 \%$ \\
\hline Hernia & 17 & $20.4 \%$ \\
\hline Dehydration & 13 & $15.4 \%$ \\
\hline
\end{tabular}




\begin{tabular}{|c|c|c|}
\hline Tachycardia & 9 & $10.9 \%$ \\
\hline Visible peristalsis & 7 & $8.8 \%$ \\
\hline Hypotension & 5 & $6.1 \%$ \\
\hline Abd. mass & 4 & $5.0 \%$ \\
\hline Fever & 2 & $2.5 \%$ \\
\hline \multicolumn{2}{|c|}{ Table 1. Physical Findings } \\
\hline
\end{tabular}

\begin{tabular}{|c|c|c|}
\hline $\begin{array}{c}\text { Cause of Bowel } \\
\text { Obstruction }\end{array}$ & $\begin{array}{c}\text { Number of } \\
\text { Patients }\end{array}$ & $\begin{array}{c}\text { Percentage of Total } \\
\text { Patients }\end{array}$ \\
\hline Adhesions & 56 & $68.29 \%$ \\
\hline Hernia & 13 & $15.85 \%$ \\
\hline Ileocaecal TB & 8 & $9.76 \%$ \\
\hline Intussusceptions & 3 & $3.66 \%$ \\
\hline Tumours & 2 & $2.44 \%$ \\
\hline Total & $\mathbf{8 2}$ & $\mathbf{1 0 0 \%}$ \\
\hline
\end{tabular}

Table 2. Various Causes of Small Bowel Obstruction (n=82)

\begin{tabular}{|c|c|c|}
\hline Complication & Number of Patients & $\begin{array}{c}\text { \% of Total } \\
\text { Patients }\end{array}$ \\
\hline Dehydration & 12 & $14.43 \%$ \\
\hline Peritonitis & 11 & $13.41 \%$ \\
\hline Gangrene & 9 & $10.97 \%$ \\
\hline $\begin{array}{c}\text { Electrolyte } \\
\text { imbalance }\end{array}$ & 4 & $4.88 \%$ \\
\hline Sepsis & 4 & $4.88 \%$ \\
\hline Gut perforation & 2 & $2.44 \%$ \\
\hline Renal failure & 1 & $1.22 \%$ \\
\hline \multicolumn{2}{|c|}{ Table 3. Pre-Operative Complications } \\
\hline
\end{tabular}

\begin{tabular}{|c|c|c|}
\hline Complication & $\begin{array}{c}\text { Number of } \\
\text { Patients }\end{array}$ & $\begin{array}{c}\text { \% of Total } \\
\text { Patients }\end{array}$ \\
\hline Recurrence & 3 & $3.66 \%$ \\
\hline Wound infection & 2 & $2.44 \%$ \\
\hline Fistula formation & 1 & $1.22 \%$ \\
\hline Burst abdomen & 1 & $1.22 \%$ \\
\hline Deep vein thrombosis & 1 & $1.22 \%$ \\
\hline Total & 8 & $9.76 \%$ \\
\hline \multicolumn{3}{|c|}{ Table 4. Post-Operative Complications } \\
\hline
\end{tabular}

\section{DISCUSSION}

Small bowel obstruction is an important cause of acute abdomen and according to previous studies it accounts for at least $20 \%$ of all admissions to a surgical service. ${ }^{1}$ In this study $63(76.82 \%)$ cases were male, while 19 (23.17\%) were female giving a male: female ratio of $3.3: 1$, which showed a male preponderance and it is comparable to an earlier study by Ngugi JK et al, ${ }^{15}$ where the sex ratio was found to be 3: 1 in cases of bowel obstruction secondary to adhesions. The mean age was 37.50 years with a range of 13 - 94 years. The peak age group was in the third and fourth decades accounting for $53.2 \%$ compared to the fifth decade in the United Kingdom. ${ }^{16}$ This group comprises the most productive work force of any country.

The pattern of small bowel obstruction at RIMS compares to that in the western advanced countries, which contrasts earlier reports by McAdam WJ17 and Garrido PI where strangulated hernias were found to be the commonest cause in developing countries. The main cause of bowel obstruction at RIMS is due to adhesions and bands, mainly associated with previous abdominal surgeries. A small group may occur due to peritoneal infections or inflammatory conditions, for which laparotomy has not been done. ${ }^{18}$ This pattern differs with other developing countries contrary to literature. ${ }^{8}$ McEntrie et al $^{19}$ found that the commonest cause of bowel obstruction in United Kingdom was adhesions followed by neoplasms, strangulated hernias, volvulus and faecal impaction in that order. Akcakaya in Turkey noted that the most frequent cause of bowel obstruction in the developed countries is adhesions, while strangulated hernias are more common in developing countries which does not appear to be the case at RIMS.

In India Tamijmarare et $\mathrm{al}^{20}$ showed that in a study of 572 patients admitted with small bowel obstruction between 1984 and 1992, 219 patients had obstructed external hernias as the leading cause, while adhesive obstruction was second in 176 patients. India is a developing country, but the pattern of bowel obstruction compares to that of developed countries due to the fact that the health delivery in urban centres tends to simulate that of developed countries. ${ }^{18}$

Hyponatraemia was largely dependent on the duration of symptoms, which could be due to high concentration of $\mathrm{Na}^{+}$in gastro-bowel secretions. ${ }^{21} \mathrm{On}$ an average in the first 3 days of obstruction the patient had normal $\mathrm{Na}^{+}$levels and after 4 days patient had hyponatraemia. $\mathrm{Na}^{+}$levels were either normal or below normal. There was no patient with hypernatraemia. Normal $\mathrm{Na}^{+}$levels existed among patients who presented within the first 3 days. ${ }^{22}$

Patients with bowel obstruction lose $\mathrm{K}^{+}$both in secretions and urine. As the distal convoluted tubule respond to aldosterone in the shock-like state of bowel obstruction it reabsorbs $\mathrm{Na}^{+}$ions. The reabsorbed $\mathrm{Na}^{+}$is exchanged for $\mathrm{H}^{+}$ and $\mathrm{K}^{+}$. In small bowel obstruction, low $\mathrm{H}^{+}$exist due to vomiting. Since $\mathrm{H}^{+}$is also low in early obstruction, $\mathrm{K}^{+}$is lost to the tubular lumen instead. That may explain the early hypokalaemia. $\mathrm{K}^{+}$is also lost to the bowel lumen. Later on, serum $\mathrm{H}^{+}$is increased due to anaerobic metabolism and lactic acid production. The increased $\mathrm{H}^{+}$is excreted instead of $\mathrm{K}^{+}$ Thus, $\mathrm{K}^{+}$levels go up. Also on acidosis $\mathrm{H}^{+}$is pumped into the cell in exchange for $\mathrm{Na}^{+}$instead of $\mathrm{K}^{+}$. This is accentuated by high aldosterone levels that are in consonance with hypovolaemia that occurs in bowel obstruction. ${ }^{23}$

Patients with a short duration of small bowel obstruction presented with normochloraemia followed by hyperchloraemia and then hypochloraemia. This tie up with scientific explanation that most patients are assumed to have had normal levels before bowel obstruction, hyperchloraemic and then hypochloraemia. Patients followed initial hypochloraemia could be explained by the initial reabsorption of $\mathrm{Na}^{+}$. This is effected by the proximal convulated tubule. This is more effective before aldosterone levels rise. The $\mathrm{Na}^{+}$is followed by $\mathrm{Cl}^{-}$for electroneutrality in the proximal convulated tubule, thus $\mathrm{Cl}^{-}$levels rise initially. ${ }^{24}$

Later hypochloraemia could be explained by as hypovolaemia develops, aldosterone levels rise. This favours $\mathrm{Na}^{+}$reabsorption in the distal convulated tubules. In the distal convulated tubules, $\mathrm{Na}^{+}$reabsorption is in exchange for $\mathrm{K}^{+}$and $\mathrm{H}^{+}$. Hypochloraemia existed in patients presenting after 6 days of obstruction. Thus, the $\mathrm{Na}^{+}$reabsorbed in the distal convulated tubules in the presence of aldosterone is exchanged for $\mathrm{H}^{+}$instead of $\mathrm{K}^{+}$. Thus, $\mathrm{Cl}$ - ions will be lost in the form of paradoxical aciduria and even when the transient hypokalaemia shifts to hyperkalaemia hypovolaemic shock exists. Thus, there is anaerobic respiration and lactic acidosis. 
The $\mathrm{H}^{+}$excreted is still followed by $\mathrm{Cl}^{-}$, thus favouring $\mathrm{Cl}^{-}$ion loss in urine further with consequent hypochloraemia. 25

\section{CONCLUSION}

The study was conducted on 82 patients admitted with the diagnosis of small bowel obstruction during the 2-year period of October 2013 to September 2015 in the surgical wards of Regional Institute of Medical Sciences (RIMS), Imphal and from the above study, following conclusions were reachedThe commonly affected age group is 21 - 40 years accounting for more than half of the patients and is predominantly present in the males with a male-to-female ratio of 3.2: 1 . The most common cause being adhesions from previous abdominal surgeries followed by strangulated hernias. Plain abdominal $\mathrm{x}$-ray is the main imaging investigation carried out and found out to be diagnostic in more than $60 \%$ of cases. Dehydration was present in most of the patients and resuscitation was essential in all cases of small bowel obstruction. Operative management was the mainstay of treatment in more than two-thirds of cases and rest of the cases were managed non-operatively. Duration of obstruction influenced serum electrolyte levels and site of obstruction had minimum influence over the serum potassium levels, but site of obstruction does have effect over the serum sodium and chloride levels until unless time has not been controlled. Strangulation influences serum potassium levels but does not seem to influence serum sodium, chloride and bicarbonate levels. Hospital stay and mortality rate were higher in patients who presented late.

\section{REFERENCES}

[1] Fischer JE, Nussbaun MS. Manifestations of gastrobowel disease: Principles of surgery. $7^{\text {th }}$ edn. New York: McGraw-Hill International Editions 1999.

[2] Botteril ID, Sagar PM. Bowel obstruction. J Surg Pak Int 1998;43(1):221-6.

[3] Botteril ID, Sagar PM. Bowel obstruction. J Surg Pak Int 2000;48(3):35-9.

[4] Corry D, Lunnis PJ. The acute abdomen. In: Brain WB, Simon PB, eds. Hamilton Bailey's physical signs: demonstration of physical signs in clinical Surgery. 18 th edn. Oxford: Butterworth-Heinemann International edition 1997: p. 307-11.

[5] Muyembe VM, Suleman N. Bowel obstruction at a provincial hospital in Kenya. East Afr Med J 2000;77(8):440-3.

[6] Adesunkanmi AR, Agbakwuru EA. Changing pattern of acute intestinal obstruction in a tropical population. East Afr Med J 1996;73(11):727-31.

[7] Wangensteen $\mathrm{OH}$. Historical aspect of the management of the acute intestinal obstruction. Surg 1969;65(2):363-83.

[8] Williams SB, Greenspon J, Young HA, et al. Small bowel obstruction: conservative versus surgical management. Dis Colon Rectum 2005;48(6):1140-6.
[9] Beck DE, Opelka FG, Bailey HR. Incidence of smallbowel obstruction and adhesiolysis after open colorectal surgery. Ann Surg 2010;33(13):1049-51.

[10] Playforth RH, Holloway JB, Griffen WO Jr. Mechanical small bowel obstruction: a plea for earlier surgical intervention. Ann Surg 1970;171(5):783-8.

[11] Kloiber HD. Importance of radioimages in cases of small bowel obstruction. Clin J Radio 1999;112(4):513-6.

[12] Gleeson JA. The small intestine. In: Sutton D, Whitehouse RW, eds. Textbook of Radiology and Imaging. $6^{\text {th }}$ edn. Churchill Livingstone 1998: p. 86390.

[13] Brewer BJ, Golden GT, Hitch DC, et al. Abdominal pain: An analysis of 1,000 consecutive cases in a University hospital emergency room. Am J Surg 1976;131(2):219-23.

[14] Miller G, Boman J, Shrier I, et al. Natural history of patients with adhesive small bowel obstruction. Brit J Surg 2000;87(9):1240-7.

[15] Ngugi JK. A study of bowel obstruction from adhesions at Kenyatta National Hospital [Dissertation]. Nairobi: University of Nairobi 1999.

[16] Akcakaya A, Alimoglu O, Hevenk T, et al. Mechanical intestinal obstruction caused by abdominal wall hernias. Ulus Trauma Derg (Turkey) 2000;6(4):260-5.

[17] McAdam WJ. A three year review of bowel obstruction. East Afr J Med 1969;38:536-44.

[18] Quatromoni JC, Rossolf L, Halls JM, et al. Early postoperative small bowel obstruction. Ann Surg 1980;191(1):72-4.

[19] McEntrie G, Pender D, Mulvin D, et al. Current spectrum of intestinal obstruction. $\mathrm{Br} \quad \mathrm{J}$ Surg 1987;74:976-80.

[20] Tamijmarare A, Chandra S, Smile SR. Clinical aspects of adhesive bowel obstruction. Tropical Gastroenterology 2000;21(3):141-3.

[21] Shires GT, Sabiston DC. Bowel obstruction. In: Sabiston DC, Lyerly HK, eds. Sabiston Textbook of surgery: The biological basis of modern surgical peactice. $15^{\text {th }}$ edn Philadelphia: WB Saunders 1997: p. 92-111.

[22] Weisbrodt NW. Patterns of bowel motility. Ann Rev Physio 1981;43:21-31.

[23] Davenport HW. The ABC of acid base chemistry. 6 $6^{\text {th }}$ edn. New York: University of Chicago Press 2002.

[24] Schafer JA. Mechanisms coupling the absorption of solute and water in the proximal nephron. Kidney Int J 2004;347:708-13.

[25] Kassirer JP, Berkman PM, Lawrenz DR, et al. The critical role of chloride in the correction of hypokalemic alkalosis in man. Am J Med 1965;38(2):172-89. 